\title{
Culture as a Protective Factor: The Use of Storytelling in a Teen Pregnancy and STI Prevention Curriculum
}

Holly Manaseri ${ }^{*}$ Kelly Roberts, Kathleen Stofocik, Naomi Manuel and Denise Uehara

Center on Disability Studies, University of Hawaii, USA

*Corresponding author: Holly Manaseri, District Educational Specialist, Hilo-Waiakea Complex, Hawaii, USA, Tel: 808-888-2719; E-mail:hmanaser@hawaii.edu

Rec date: Jan 11, 2014, Acc date: Sep 20, 2014; Pub date: Sep 25, 2014

Copyright:@ 2014 Manaseri $\mathrm{H}$ et al. This is an open-access article distributed under the terms of the Creative Commons Attribution License, which permits unrestricted use, distribution, and reproduction in any medium, provided the original author and source are credited.

\begin{abstract}
The University of Hawaii Center on Disability Studies, in collaboration with two community partners, Planned Parenthood of Hawaii and ALU LIKE, Inc. has developed the Pono Choices teen pregnancy and Sexually Transmitted Infections (STI) curriculum for Hawaii middle school youth. Pono Choices draws explicitly on Hawaiian cultural values and cultural practices as the foundation for the curriculum. The partners also created an original Hawaiian cultural story to reinforce the teen pregnancy and STI prevention message. This creative approach culture as a protective factor to prevent an unintended pregnancy or STI, has merit for wider consideration in broadening work in the health education arena, especially in working with difficult to reach populations.
\end{abstract}

\section{Introduction}

In recent years, the United States has experienced many positive trends in youth behaviors, including decreased rates of teen pregnancy (Darroch and Singh, 1998), substance abuse (National Institute on Drug Abuse, 2006), high school dropout rates (Laird, DeBell, and Chapman, 2006), and youth gang involvement (Egley and Ritz, 2006). However, the Native Hawaiian and Pacific Islander teen pregnancy rate in Hawaii is 177 per 1,000 females aged 15-19 which is disproportionately higher than the teen pregnancy rate of White, Asian and Black teen females in Hawaii combined (Hawaii Health Data Warehouse, 2013). In order to successfully transition into healthy adulthood, all young people need positive youth development messages. A university-community partnership, in the state of Hawaii, is addressing the high rates of teen pregnancy and sexually transmitted infections (STIs) through the development of the Pono Choices Teen Pregnancy and Sexually Transmitted Infection (STI) prevention curriculum which utilizes a creative approach to connect with youth at risk of teen pregnancy or STIs.

\section{A Youth Development approach to Address Risk}

Extensive research has identified factors that impact youth problem behaviors such as substance use, violence, suicide ideation, and early sexual activity. Studies have found, the more risk factors an adolescent has, the greater the likelihood of problem behaviour. Youth development is the on-going growth process in which all youth attempt to 1) meet the basic personal and social needs to feel cared for and to be safe, valued, useful, and spiritually grounded and 2) build skills and competencies that permit functioning and contribution in daily life (Pittman, O’Brien, Kimball, 1993). Youth development offers powerful opportunities for adolescent pregnancy prevention, reaching youth who are ambivalent about parenthood and lack motivation to delay childbearing. By providing youth with opportunities, these programs encourage teens to delay pregnancy until they are emotionally, psychologically, and financially prepared for the responsibilities of parenting. Addressing some of the risk factors, through curriculum-based sexual health education, has been shown to have a positive effect on reducing early sexual initiation (Kirby, 2007).

Youth development programs encourage and support young people as they mature by building up protective factors and a resilient personality in order to better able cope with risk factors and life challenges. Youth exposed to this approach are less likely to be involved in problem behaviors and more likely to do well in school and in life. In today's world of prevention and treatment of social problems the term risk factor refers to "individual or environment hazards that increase an individual's vulnerability to negative developmental outcomes. A risk factor approach assumes that there are multiple, and often overlapping, risk factors in an individual's background that lead to adverse outcomes. Furthermore, it posits that it is the cumulation (sic) of risk in the life course that is most strongly related to adversity" (Thornberry, 2001, p. 32). The concept of protective factors is instrumental in shifting the focus from what's wrong with youth to what can be done to facilitate the healthy development of youth. The term, Protective Factor, is sometimes used interchangeably with the terms: Resiliency, Developmental Assets, or positive youth development. Each of these terms refers to a strengthsbased approach of working with children, youth, and the community. Resilient individuals have been described as having healthy expectancies, a sense of optimism, internal locus of control, problemsolving skills, self- discipline, and a sense of humor (Garmezy 1985; Rutter 1979; Seligman 1992; Werner 1988; Wolin 1993).

\section{Study Purpose: Background and Need}

In 2010, the Office of Adolescent Health (OAH) awarded the University of Hawaii's Center on Disability Studies (UH-CDS) a cooperative agreement through a competitive process to support the development and testing of innovative strategies for preventing teen pregnancy. Hawaii's teen pregnancy rate is 12 th in the nation and Hawaii has historically had high rates of STIs prompting a need for a locally developed age appropriate prevention curriculum. The University of Hawaii-CDS collaborated with two community organizations, Planned Parenthood of Hawaii and ALU LIKE, Inc. a 
native Hawaiian serving organization to develop a curriculum-based intervention and test its effectiveness through a rigorous randomized study of middle school youth in the state of Hawaii. A collaborative workgroup was formed and the Hawaii Department of Education (DOE), a single unified school district, provided oversight in the implementation of the study to 36 randomly assigned public and public charter schools.

Curriculum-based programs are based on written curriculum that is implemented with groups of adolescents in schools, clinics, or community settings. Studies on curriculum-based programs have shown that these programs improve sexual protective factors by delaying sexual activity, reducing the frequency of sex, reducing the number of sexual partners, and increasing condom and contraceptive use (Kirby, 2007). (Overall, approximately two-thirds of curriculumbased programs having met evidence-based standards (WHO, 2009) have had positive effects on adolescent sexual behavior. The goal of Pono Choices is to reduce the number of teen pregnancies and incidences of STIs; increase positive bonding in the school and community; increase sense of self-identity and self-efficacy; and improve expectations for the future (Kirby, 2007; Bearinger, Sieving and Ferguson, 2007; Nitz, 1999). Pono Choices uses the social learning theory to increase a student's personal belief in being able to prevent an unintended pregnancy and STI. Curriculum-based programs that draw upon social behavioral theories to enhance student's self-efficacy around teen pregnancy and STI prevention have correlated to a reduction in unplanned teen pregnancy rates (As-Sanie, Gantt, Rosenthal, 2004).

\section{A Focus on Protective Factors}

Culture has been defined as the "complex ensemble of emotions, beliefs, values, aspirations . . . that together make up behavior" (Fabrega, 1992:561). Culture is transmitted through language and is constantly changing. It includes the stories, songs, art, and literature of a people. In essence, it is the framework in which childhood socialization takes place (Beauvais, 1992). Research shows that strong cultural identification makes adolescents less vulnerable to risk factors for drug use and more able to benefit from protective factors than adolescents who lack this identification (Zickler, 1999). Moran and Reaman (in press) cite a prevention program, Project CHARLIE (Chemical Abuse Resolution Lies in Education), that found a significant correlation between increased affiliation with one's culture and decreased alcohol and drug use yet similar studies have not been conducted in the area of teen pregnancy and STI prevention. Community organizations that have implemented evidence-based teen pregnancy prevention curricula acknowledged the lack of cultural practices in the curricula, which may hinder the youths' self-efficacy in teen pregnancy prevention (Ott, Ruse, Resseguie, Smith and Woodcox, 2010).

The Pono Choices curriculum has utilized a place-based approach, whereby the local traditions, Hawaiian cultural practices, and specific place, engage and provide access for local students' introduction to sexual health topics and reinforce the teen pregnancy and STI Prevention message. This approach is not a word of the day, but rather draws upon a place-based approach. Place -based education differs from conventional text and classroom-based education in that it draws from students' local community as one of the primary resources for learning. Place-based education promotes learning that is rooted in what is local-the unique history, environment, culture, economy, literature, and art of a particular place[-that is, in students' own "place" or immediate schoolyard, neighbourhood, town or community. It was our intent to cultivate an awareness of and sensitivity to Hawai'i's cultural approach to learning in the hope that it will bridge one's own educational framework with that of the base culture and its values of 'ohana (family), community, and place.

The creation of the original story -The Voyage of the Wa'a Kaulua, was a collaborative process and involved community partners and codevelopers of the curriculum, ALU LIKE, Inc., Planned Parenthood of Hawaii, as well as the Center on Disability Studies media specialists, and the talents of a cultural storyteller and a local artist who provided original images to accompany the story. The story serves to actualize Hawaiian cultural values that are used throughout the curriculum and to reinforce the primary prevention message in the sexual health content. Storytelling is inherent to many indigenous cultures. Implementing it, as part of a prevention strategy, is compatible with these cultures. Cross (1998) recommends storytelling as a family strategy stating "in passing on the stories of our lives, we pass on skills to our children, and we parent for resiliency" (Cross, 1998:152)".

Students in the Pono Choices curriculum listen to the story and take notes next to the accompanying illustrations in their Pono Choices student workbook. At the conclusion of the chapter students participate in comprehension questions. The Voyage of the Wa'a Kaulua is about the journey of the wa'a (a Hawaiian voyaging canoe) and how it relates to two adolescents on their journey toward their goals and dreams. One chapter in the story corresponds to the teen pregnancy and STI prevention lesson about the importance of developing effective communication skills- an essential skill in refusing unwanted sexual pressure. Students are introduced to the Hawaiian cultural value, Nohona. Nohona is defined in the Pono Choices curriculum and means how you communicate and relate to others. In the chapter, two youth, Ka'iwi and Pailolo, talk about the differences in their families and their parents' communication styles. Ka'iwi's parents were considered to have a healthy nohona because they communicated with each other respectfully, but Pailolo's parents did not. Their kupuna (elder in the community) facilitates the discussion in the story. As the two youth analyze the effectiveness of each communication style the importance of healthy communication in relationships is emphasized.

Bernard (1991) describes three protective factors as essential conditions necessary to mitigate or buffer the effects of risk: Caring and Support; high expectations; and opportunities for meaningful participation. These protective factors are evident throughout the stories told in the Pono Choices curriculum. In the example of the Nohana story, students are able to examine the skill of recognizing healthy, unhealthy, and abusive relationships after recognizing in the story the role of what a caring and supportive relationship looks like and what the expectations are for communicating in a respectful way as the kupuna in the story serves as a supportive guide to the youth. Lastly, in the stories used throughout the Pono Choices curriculum, youth are able to see evidence of how the characters work through real-life situations that they also may be facing. The stories make these situations relevant and meaningful to the students. In turn, the stories used throughout the curriculum continue to build upon one another in an intentional effort to build resiliency.

\section{Pilot Testing the Design of the Curriculum}

As part of the curriculum development process and readiness for efficacy testing, we implemented a rigorous pilot test protocol 
involving all developers. Pilot testing was a critical element of the curriculum development process to ensure the following: 1) benchmarking the appropriate developmental level of the curriculum to address middle school sexual health; 2) cultural responsiveness that reflects the diversity of our island state; 3 ) delivery of intended content and originally developed story; 4) embedded design targets such as self-efficacy, self-identity and future aspirations outcomes; 5) feasibility to implement in various middle schools across the state; 6) flexibility of content and pedagogy for teachers to authentically deliver with comfort; 7) student responsiveness to the overall content and delivery of the curriculum.

A series of three pilot tests took place over the course of six months with the findings from each test used to make program and curriculum improvements. The first pilot test took place on a neighbor island with information collected via surveys and a student group interview that served as data driven platform to improve the curriculum for the next phase of pilot testing. The majority of students were multi-racial reflecting the composition of classrooms across the state of Hawaii. The second pilot test took place on an Oahu middle school a few months after the first pilot test and the students also mirrored the ethnic diversity common to Hawaii. Results informed the implementation of the third pilot test which took place immediately following the second pilot test. On the spot curriculum changes were made after pilot two and implemented with a smaller sample of students who participated in pilot two.

Overall, students' reactions and responses gathered during all three pilot tests provided invaluable insights to ensuring that Pono Choices was culturally responsive, developmentally appropriate and engaging for middle school youth in Hawaii. All three pilots resulted in positive responses when students were asked about their experiences learning the curriculum. For example, students identified enjoying the activities and games that served to introduce and reinforce specific content such as learning about STIs. In addition, they identified favorite lessons based on certain modules grounded in a Hawaiian cultural value. They provided specific feedback about the original story such as wanting to include more visuals and having opportunity to role play some of the narrative. The curriculum developers were given formal reports that summarized the feedback from each pilot test and comments related to curriculum improvements (ie. power point had too much words; more partner activities) were considered and adjustments made within the curriculum.

\section{Conclusion}

The Pono Choices curriculum is currently being tested for efficacy through a randomized controlled trial, final results will be available in 2015. Much can be learned about the effectiveness of reducing teen pregnancy and STIs for youth when engaging them in a curriculumbased prevention that has culturally compatible strategies, like storytelling, incorporated as an essential protective factor. This study has the potential for expanding the evidence based focus beyond the knowledge and skill acquisition model to a more holistic approach that addresses youth as cultural beings who absorb information and act upon it through a cultural lens. Building youth resilience requires dynamic approaches, the Pono Choices curriculum provides one promising contribution to this endeavour, storytelling. 